\title{
Synergistic Effect of H1-Antihistamines on Topical Corticosteroids for Pruritus in Atopic Dermatitis: A Systematic Review and Meta-Analysis
}

\author{
Min Seok Hur, Yong Beom Choe, Kyu Joong Ahn, Yang Won Lee \\ Department of Dermatology, Konkuk University School of Medicine, Seoul, Korea
}

Background: Although oral antihistamines (H1-histamine receptor antagonists) are the main treatment option for pruritus in general skin dermatosis, their effect in treating pruritus of atopic dermatitis (AD) has not yet been established. Objective: We conducted a systematic review and meta-analysis to evaluate the effectiveness of combined therapy of $\mathrm{H} 1$-antihistamines and topical steroids. Methods: We systematically searched MEDLINE, Embase, and CENTRAL databases for articles published from 1967 to 2015. We identified 1,206 studies and assessed their titles, abstract, and full-text. Random effects meta-analysis was used to calculate mean differences (MD) with 95\% confidence intervals (Cl). Results: Two studies satisfying the inclusion criteria of antihistamine therapy with mandatory topical steroid use were selected. Comparing antihistamine monotherapy with combination therapy, patients treated with the addition of antihistamine to topical corticosteroids showed a statistically significant clinical improvement (standard MD, $-0.24 ; 95 \% \mathrm{Cl},-0.42$ to $-0.05 ; p=0.01)$. Conclusion: $\mathrm{H} 1$-antihistamines may have a synergistic effect when combined with topical steroids by influencing various associative factors of chronic pruritus in AD.

Received November 9, 2018, Revised January 15, 2019, Accepted for publication February 27, 2019

Corresponding author: Yang Won Lee, Department of Dermatology, Konkuk University School of Medicine, 120 Neungdong-ro, Gwangjin-gu, Seoul 05029, Korea. Tel: 82-2-2030-5172, Fax: 82-2-2030-5179, E-mail: 20050078@ kuh.ac.kr

ORCID: https://orcid.org/0000-0003-1268-1248

This is an Open Access article distributed under the terms of the Creative Commons Attribution Non-Commercial License (http://creativecommons. org/licenses/by-nc/4.0) which permits unrestricted non-commercial use, distribution, and reproduction in any medium, provided the original work is properly cited.

Copyright (c) The Korean Dermatological Association and The Korean Society for Investigative Dermatology
(Ann Dermatol 31(4) 420 425, 2019)

-Keywords-

Dermatitis, atopic, Histamine $\mathrm{H} 1$ antagonists, Meta-analysis, Pruritus

\section{INTRODUCTION}

Atopic dermatitis (AD) is the most prevalent dermatosis in children that often progresses to chronic dermatitis in adulthood. The prevalence of AD in early childhood is $15 \%$ to $20 \%$ in industrialized nations and decreases to $1 \%$ to $3 \%$ in adulthood. AD is a chronic relapsing skin disorder that affects social interaction and the quality of life of patients.

$\mathrm{H} 1$-antihistamines have been used widely to treat pruritus in $\mathrm{AD}$ and to treat allergic inflammatory diseases and pruritic dermatoses. Nonetheless, the efficacy of antihistamine drugs has not been clearly established for pruritus in AD. Previously published meta-analyses have examined the effectiveness of $\mathrm{H} 1$-antihistamine therapy for $\mathrm{AD}$, but the use of $\mathrm{H} 1$-antihistamines as monotherapy still remains controversial $^{1,2}$.

Although the evidence for $\mathrm{H} 1$-antihistamine monotherapy is inconclusive, combination therapy with topical applications, systemic drugs, phototherapy, avoidance of triggering factors, and education are the basic therapeutic strategy in AD. For example, Korean Atopic Dermatitis Association recommended combination therapy of $\mathrm{H} 1$-antihistamine and topical glucocorticoids with high level of evidence $^{3}$. However, in addition to evidence based on clinical improvement, there are a few researchs for mechanism of synergic effect of the combination therapy on pru- 
ritus in $\mathrm{AD}$ patients.

This study evaluated clinical efficacy from the existing literature for a combination of $\mathrm{H} 1$-antihistamine with topical corticosteroid, and also provided a review of immunological mechanism.

\section{MATERIALS AND METHODS}

\section{Protocol and search strategy}

We conducted a systematic review and meta-analysis for confirming the efficacy of antihistamine as an adjunct to topical corticosteroid application in the treatment of AD.

The Preferred Reporting Items for Systemic Reviews and Meta-Analysis (PRISMA) Statement was used for this systematic review, which was conducted in accordance to PRISMA statement guideline. Search terms included "atopic dermatitis" or "eczema" for participants, "antihistamine" or "steroid" or "placebo" for intervention, and "pruritus" or "itch" for outcome measures in the MEDLINE, Embase, and CENTRAL databases for studies published from 1967 to 2015.

\section{Search methods for identification of studies}

We used the following the PICO process as the search strategy in the literature:

- Patient: atopic dermatitis (synonym, eczema)
- Intervention: histamine antagonist (synonym, H1-receptor blocker)

- Control: topical treatment, steroid, corticosteroid, hydrocortisone, placebo

- Outcome: itch (synonym. itching, pruritus), severity, SCORAD (Severity Scoring of Atopic Dermatitis)

\section{Eligibility criteria}

We included randomized controlled trails (RCTs) and non-randomized controlled trails (non-RCTs) to evaluate the effectiveness of $\mathrm{H} 1$-antihistamines as adjunctive therapy for topical steroid application. All participants identified as having a clinical diagnosis of AD and using topical steroid as basic treatment were included. Oral antihistamine was included as an additive therapy but was limited to the $\mathrm{H} 1$ class of histamine receptor antagonists. The use of other therapeutic agents, such as emollients, topical antihistamine, oral corticosteroids, and immunomodulatory drugs, except for placebo, was excluded.

\section{RESULTS}

\section{Results of the search}

We identified 1,206 studies through the search engine, and 139 duplicate papers were excluded. We identified 153 studies following primary examination of the titles of

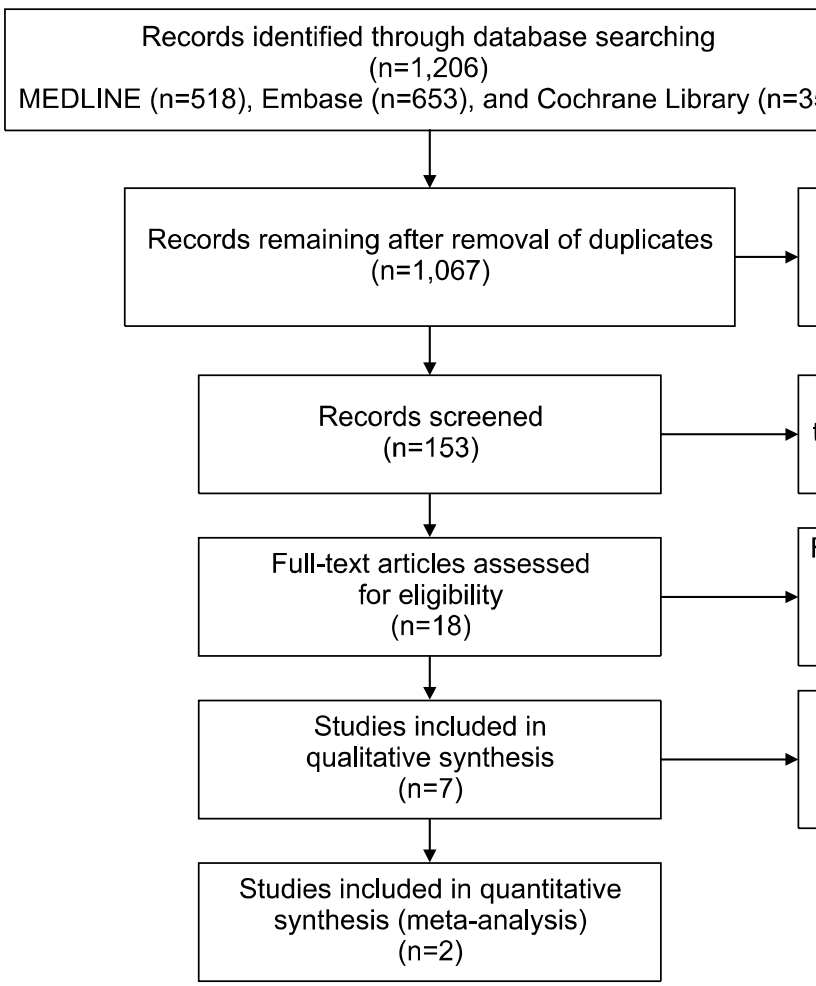

Records excluded ( $n=914$; reviews, letters, commentaries or case reports)

Records excluded through abstract analysis $(n=135)$

ull-text articles excluded $(n=11$; because of no control arm or they did not show clear date)

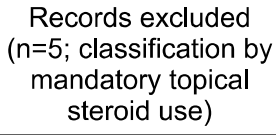

Records excluded ( $n=5$; classification by mandatory topical steroid use)

Fig. 1. Flow diagram of the research strategy. Two studies were included in our meta-analysis which satisfied the inclusion criteria. 
the unique 1,067 papers; 18 of these were selected following abstract evaluation for further analysis. The eligibility assessment was performed by two authors. Seven RCTs met our inclusion criteria, but only two of these studies met the stringent standards, which were the mandatory application of topical steroid and comprising only patients with AD (Fig. 1).

\section{Excluded studies}

Four RCTs and a non-RCT were excluded because their study design did not meet our standards. In the four RCTs, the use of topical steroid were either not mandatory, allowed if needed, or not mentioned. In the non-RCT, patients applied both topical steroid and emollients.

\section{Included studies}

We included two studies after a full text assessment: one RCT and one non-RCT. The study by Kawashima et al. ${ }^{4}$ was designed as a randomized double-blind, placebo-controlled, parallel group study for a second-generation antihistamine (fexofenadine) in combination with hydrocortisone butyrate $1 \%$ cream. In both groups, placebo was administered in the first week, and the experiment was divided into placebo and experimental groups in the following week. Clinical improvement was compared between the placebo-treated and antihistamine-treated groups.

In a second study by Chunharas et al. ${ }^{5}$, a second-generation antihistamine was also used (loratadine syrup) in combination with mometasone furoate $0.12 \%$ cream. All patients were divided into two groups and evaluated for clinical improvement after two weeks of treatment with antihistamine or placebo, respectively.

\section{Assessment of the effectiveness of antihistamine}

In the first study, the pruritus was measured using a 5-point scale $(0 \sim 4$ points). Both the diurnal and nocturnal measurements were added, and the extent of improvement of itching was assessed through the mean difference in scores. In the second study, itching was classified based on severity and was scored and evaluated with a 4-point scale $(0 \sim 3$ points). The evaluation was performed on days $1,5,8$, and 14 , and the mean value was used to assess the severity of pruritus.

\section{Analysis of the effectiveness of $\mathrm{H} 1$-antihistamine as adjunctive therapy}

A discrepancy was found in the results of the two studies. In the study by Kawashima et al. ${ }^{4}$, involving 300 adult patients with $A D$, the mean change of the pruritic score in the antihistamine-treated group was significantly higher than that in the placebo group $(p<0.001)$. In contrast, the

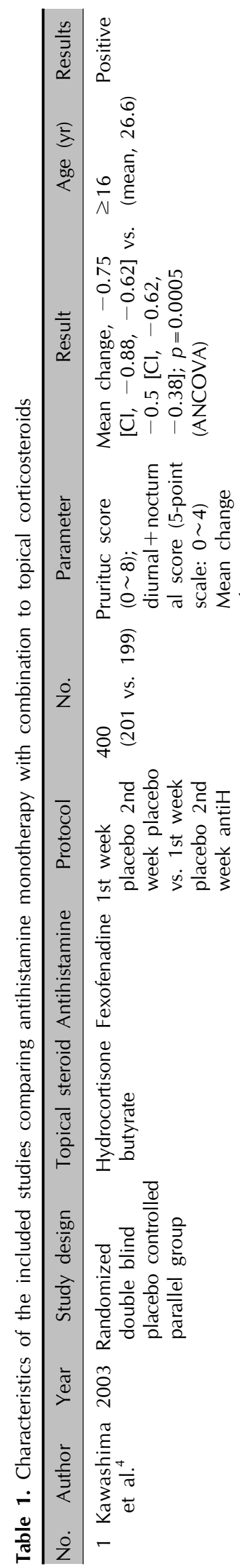

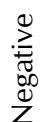

๘

$\frac{\text { ำ }}{2}$ है

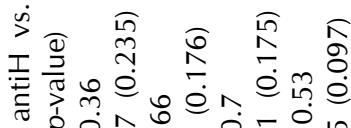

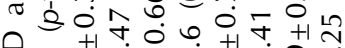

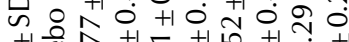

+1

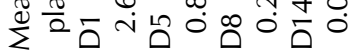

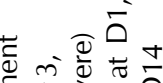

?

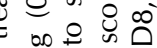

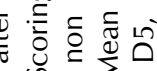

ฟั

i

我

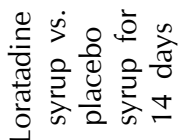

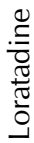

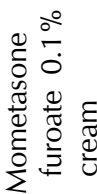

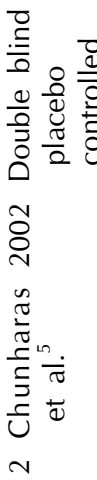




\begin{tabular}{|c|c|c|c|c|c|c|c|c|c|c|}
\hline \multirow{2}{*}{$\begin{array}{l}\text { Study or subgroup } \\
\text { Chunharas et al. }^{5}\end{array}$} & \multicolumn{3}{|c|}{ Experimental } & \multicolumn{3}{|c|}{ Control } & Weight (\%) & $\begin{array}{c}\text { Standard mean difference } \\
\text { IV, fixed, } 95 \% \mathrm{Cl}\end{array}$ & \multicolumn{2}{|c|}{$\begin{array}{c}\text { Standard mean difference } \\
\text { IV, fixed, } 95 \% \mathrm{CI}\end{array}$} \\
\hline & -2.48 & 0.62 & 24 & -2.54 & 0.5 & 24 & 10.8 & $0.10[-0.46,0.67]$ & & \\
\hline Kawashima et al. ${ }^{4}$ & -0.75 & 0.93 & 201 & -0.5 & 0.86 & 199 & 89.2 & $-0.28[-0.48,-0.08]$ & - & \\
\hline Total $(95 \% \mathrm{Cl})$ & & & 225 & & & 223 & 100.0 & $-0.24[-0.42,-0.05]$ & & \\
\hline $\begin{array}{l}\text { Heterogeneity: } \mathrm{Chi}^{2} \\
\text { Test for overall effe }\end{array}$ & $\begin{array}{l}=1.57 \\
t: Z=2\end{array}$ & $\begin{array}{l}\mathrm{df}=1 \\
.50(p\end{array}$ & $\begin{array}{l}(p=0 \\
=0.01\end{array}$ & 21); $I^{2}=$ & $=36 \%$ & & & $\begin{array}{r}-1 \\
\text { Favours }\end{array}$ & $\begin{array}{l}-0.5 \\
\text { xperimentall }\end{array}$ & $\begin{array}{lc}0 & 0.5 \\
\text { Favours [co }\end{array}$ \\
\hline
\end{tabular}

Fig. 2. Forest plot of the studies included in the meta-analysis. There was a significant difference in effectiveness of adjunctive therapy. SD: standard deviation, IV: inverse variance, $\mathrm{Cl}$ : confidence interval.

results of the study by Chunharas et al..$^{5}$ showed no difference in the therapeutic response between the loratadine-treated and placebo groups $(p=0.99)$ (Table 1). A meta-analysis of the two studies showed a standard mean difference of -0.24 (95\% confidence interval [Cl], -0.42 to -0.05$)$ points. Although Kawashima et al. ${ }^{4}$ reported a clinical improvement in pruritus following adjunctive therapy with antihistamine, the opposite result was shown by Chunharas et al. ${ }^{5}$, wherein the mean score for pruritus was reported to be slightly worse (standard mean difference, -0.28 vs. 0.10 points). These studies showed moderate heterogeneity, but the I-square $\left(I^{2}\right)$ value was less than the common reference value $\left(I^{2}<50 \%\right)$ (Fig. 2).

\section{DISCUSSION}

This systematic review and meta-analysis based on two studies suggest that antihistamine therapy as an adjunctive therapy for pruritus in $A D$ may have beneficial effects in combination with topical corticosteroid treatment.

Although pruritus is the most common symptom, with an estimated $100 \%$ prevalence in patients with $A D$, the pathogenesis of pruritus in $A D$ remains unclear. Given the damaged skin barrier, sensitization of neurons is considered as an underlying feature of chronic itching. In addition, immunological imbalance induced by chronic inflammation has been suggested to result in the overexpression of various mediators that can induce pruritus in patients with $A D^{6}$.

Chronic recalcitrant pruritus in $\mathrm{AD}$ may be associated with an immunologic dysfunction of Th2. The abnormal elevation of interleukin (IL)-4, IL-5, IL-13, and IL-31 expression indicates inflammation ${ }^{7}$. IL-31 is a cytokine produced by the Th2 cell and other cells, such as mast cells and monocytes. As IL-31 is increased in the skin and serum of patients with $A D$, it is considered a pruritogen through its binding to IL-31 receptors in the dorsal ganglia. It has also been associated with downregulation of pro-filaggrin expression ${ }^{8}$.

The role of antihistamines in the treatment of $A D$ seems to be the prevention of scratching through a sedative effect. Scratching is associated with the release of neuropeptide and opiate, which may induce the vicious itch-scratch cycle $^{9}$. The sedative effects of antihistamines can be expected to minimize repetitive behavior ${ }^{10}$.

Selective histamine $\mathrm{H} 1$-receptor antagonists also seem to have other functions. An anti-inflammatory effect of $\mathrm{H} 1$ antihistamines has been evaluated recently. Olopatadine hydrochloride has inhibitory effects on the production and secretion of inflammatory mediators, including IL-6, IL-8, IL-31, nerve growth factor (NGF), and tumor necrosis factor (TNF)- $\alpha^{11-14}$. An RCT showed that levocetirizine and desloratadine were able to reduce the plasma levels of pro-inflammatory cytokines, including IL- $1 \beta$ and IL-8, in patients with allergic rhinitis ${ }^{15}$. Other antihistamines, such as loratadine and cetirizine, have been reported to reduce serum neuropeptides, including neuropeptide $\mathrm{Y}$, vasoactive intestinal peptide stem cell factor, and $\mathrm{NGF}^{16}$. A study of stimulated NGF secretion by histamine from cultured astrocytes showed that the $\mathrm{H} 1$-histamine receptor was involved in the signal transduction pathway of $\mathrm{NGF}^{17}$. Topical corticosteroids are the cornerstone of therapy for acute pruritus associated with inflammatory skin diseases. Although the exact mechanism of action of these agents is unknown, topical corticosteroids are speculated to activate glucocorticoid receptors that inhibit cytokine activation, resulting decreased local inflammation. Although corticosteroids are believed not to have any antipruritic effects, they exert a beneficial effect on pruritus via their anti-inflammatory properties.

Topical steroid therapy can modulate the Langerhans cells in the human skin through inhibiting proinflammatory signals and enhancing tolerance ${ }^{18}$. For example, cytokines, such as TNF- $\alpha$ and IL- $1 \beta$, have been reported to decrease on the ocular surface following application of topical steroids ${ }^{19}$. Prostanoids, including prostaglandins and thromboxanes, are considered as mediators that induce pruritus in $A D$. The anti-inflammatory properties of topical steroids as inhibitors of prostaglandin synthesis mediated via the cyclooxygenase-2 pathway induce anti-pruritic ef- 
fects $^{20}$. Elevation of IL-31 levels produced by Th2 cells was observed in the skin of patients with AD. IL-31 and oncostatin $M$ receptor act as inducers of pruritus in the skin of patients with AD. Topical steroids may have beneficial effects in the control of pruritus in $A D$ through inhibition of the Th2 pathway that induced IL-31 overexpression by keratinocytes and Langerhans cell-like dendritic cells ${ }^{21}$. NGF is also affected by topical steroids. Expression of NGF in patients with keratoconjunctivitis sicca decreased following treatment with topical $0.1 \%$ prednisolone $^{22}$.

As an adjunct therapy, $\mathrm{H} 1$-histamines in combination with topical corticosteroid treatment seem to have synergistic effects on pruritus in patients with $A D$, although a previous meta-analysis evaluating $\mathrm{H} 1$-antihistamine treatment for pruritus in $A D$ was inconclusive due to inconsistent results. The synergistic effect of prednisolone and olopatadine on the AD model of hairless mice has been previously reported. Topical applications of soluble prednisolone and olopatadine hydrochloride showed a significant effect on scratching, and on NGF expression in the skin and symptoms of AD. However, chlorpheniramine did not present any synergistic effect with topical steroids $^{23}$.

Although results differed depending on the type of antihistamine agent evaluated, the anti-inflammatory effects induced by some antihistamines seemed to have a synergistic effect on the anti-inflammatory effects of topical corticosteroids. The common mechanism of action of antihistamines and steroids on IL-31 and NGF is particularly remarkable. IL-31 and NGF are known to be important causative agents of neural sensitization that are associated with chronic pruritus. Moreover, antihistamines also cause histopathological changes of the neural systems involved in the maintenance of chronic recalcitrant pruritus in $\mathrm{AD}^{24}$. Therefore, this anti-inflammatory activity may contribute to improved treatment of pruritus in AD.

In addition, the sedative effect of $\mathrm{H} 1$-antihistamine therapy can help improve neurogenic components and scratching behavior. The neurogenic component to pruritus is considered to be induced by psychological factors, including anxiety, stress, and depression ${ }^{25,26}$. The histaminergic neuron system has been shown to facilitate wakefulness, pain, and itching ${ }^{27}$. A study using a murine model considered that the repetitive behavior of scratching is also related to an interaction between the histamine $\mathrm{H} 1$ and $\mu$-opioid receptors. In the study, histamine and morphine had an additive effect, and chlorpheniramine and naloxone inhibited histamine-induced scratching behavior ${ }^{28}$. A comparative study with diazepam also showed that $\mathrm{H} 1$-antihistamine treatment was able to block scratching behavior in mice $^{29}$. H1-antihistamine has been suggested to not only have a sedative effect, but also have a central effect that can modify behavioral pruritus in $\mathrm{AD}^{29}$.

This review had some limitations. First, only few studies included patients with AD who used topical steroid as the treatment modality. Second, in our meta-analysis, we compared the changes in the averages of quantitative data before and after treatment, but the size of the effect was relatively small. In addition, the information from the funnel plot was insufficient to evaluate publication bias due to the small number of studies. Third, the assessment methods used in the two studies were different. Because the scale of the clinical index of severity differed, we used an adjusted scale to normalize the scales. Although our methods can facilitate the comparison of the results of the two studies, an extended scale may not accurately reflect the original results.

Despite the limitations, our results are noteworthy. Through the increased understanding of the etiology of pruritus in chronic skin disorders, chronic pruritus is increasingly being associated with immunological dysregulation and neuronal sensitization. Although many studies have indicated only the additional effects on immunomodulatory activity, $\mathrm{H} 1$-antihistamines may also have other effects such as neural sensitization and central behavior modeling. Further RCTs are needed to clarify the physiological effects of $\mathrm{H} 1$-antihistamines in pruritus.

From the present results, $\mathrm{H} 1$-antihistamine treatment as an adjunct to topical corticosteroid may be considered to be effective for pruritus in AD. Although guidelines for monotherapy using $\mathrm{H} 1$-antihistamines to treat pruritus in $A D$ have not been established, the anti-inflammatory effect of corticosteroids seems to have a synergistic effect on antihistamine activity, and additional effects of $\mathrm{H} 1$-antihistamines may be expected on mechanisms related to inhibition of neural sensitization and modification of scratching behavior.

\section{CONFLICTS OF INTEREST}

The authors have nothing to disclose.

\section{ORCID}

Min Seok Hur, https://orcid.org/0000-0002-8354-9618 Yong Beom Choe, https://orcid.org/0000-0002-3074-7602 Kyu Joong Ahn, https://orcid.org/0000-0003-2729-7978 Yang Won Lee, https://orcid.org/0000-0003-1268-1248 


\section{REFERENCES}

1. Apfelbacher CJ, van Zuuren EJ, Fedorowicz Z, Jupiter A, Matterne $\mathrm{U}$, Weisshaar E. Oral $\mathrm{H} 1$ antihistamines as monotherapy for eczema. Cochrane Database Syst Rev 2013;(2):CD007770.

2. Church MK, Maurer M. H1-antihistamines and itch in atopic dermatitis. Exp Dermatol 2015;24:332-333.

3. Kim JE, Kim HJ, Lew BL, Lee $\mathrm{KH}$, Hong SP, Jang $\mathrm{YH}$, et al. Consensus guidelines for the treatment of atopic dermatitis in Korea (part I): general management and topical treatment. Ann Dermatol 2015;27:563-577.

4. Kawashima $M$, Tango $T$, Noguchi $T$, Inagi $M$, Nakagawa $H$, Harada S. Addition of fexofenadine to a topical corticosteroid reduces the pruritus associated with atopic dermatitis in a 1-week randomized, multicentre, double-blind, placebo-controlled, parallel-group study. $\mathrm{Br} J$ Dermatol 2003;148:1212-1221.

5. Chunharas A, Wisuthsarewong W, Wananukul S, Viravan S. Therapeutic efficacy and safety of loratadine syrup in childhood atopic dermatitis treated with mometasone furoate 0.1 per cent cream. J Med Assoc Thai 2002;85: 482-487.

6. Yosipovitch G, Papoiu AD. What causes itch in atopic dermatitis? Curr Allergy Asthma Rep 2008;8:306-311.

7. Raap U, Weißmantel S, Gehring M, Eisenberg AM, Kapp A, Fölster-Holst R. IL-31 significantly correlates with disease activity and Th2 cytokine levels in children with atopic dermatitis. Pediatr Allergy Immunol 2012;23:285-288.

8. Grundmann S, Ständer S. Chronic pruritus: clinics and treatment. Ann Dermatol 2011;23:1-11.

9. Yosipovitch G, Ishiuji Y, Patel TS, Hicks MI, Oshiro Y, Kraft $\mathrm{RA}$, et al. The brain processing of scratching. J Invest Dermatol 2008;128:1806-1811.

10. Krause L, Shuster S. Mechanism of action of antipruritic drugs. Br Med J (Clin Res Ed) 1983;287:1199-1200.

11. Cook EB, Stahl JL, Barney NP, Graziano FM. Olopatadine inhibits TNFalpha release from human conjunctival mast cells. Ann Allergy Asthma Immunol 2000;84:504-508.

12. Yanni JM, Weimer LK, Sharif NA, Xu SX, Gamache DA, Spellman JM. Inhibition of histamine-induced human conjunctival epithelial cell responses by ocular allergy drugs. Arch Ophthalmol 1999;117:643-647.

13. Murota H, El-latif MA, Tamura T, Katayama I. Olopatadine hydrochloride decreases tissue interleukin-31 levels in an atopic dermatitis mouse model. Acta Derm Venereol 2014;94:78-79.

14. Tamura T, Komai M. Effect of olopatadine hydrochloride, an anti-histamine drug, on rhinitis induced by intranasal instillation of toluene-2,4-diisocyanate in rats. Int Immunopharmacol 2008;8:916-921.

15. Bocşan $\mathrm{Cl}$, Bujor $\mathrm{Al}$, Miron $\mathrm{N}$, Vesa ŞC, Deleanu $\mathrm{D}$, Buzoianu AD. In vivo anti-inflammatory effect of $\mathrm{H} 1$ antihistamines in allergic rhinitis: a randomized clinical trial. Balkan Med J 2015;32:352-358.

16. Başak PY, Vural H, Kazanoglu OO, Erturan I, Buyukbayram HI. Effects of loratadine and cetirizine on serum levels of neuropeptides in patients with chronic urticaria. Int J Dermatol 2014;53:1526-1530.

17. Lipnik-Stangelj M, Carman-Krzan M. Activation of histamine $\mathrm{H} 1$-receptor enhances neurotrophic factor secretion from cultured astrocytes. Inflamm Res 2004;53:245-252.

18. Ali MA, Thrower SL, Hanna SJ, Coulman SA, Birchall JC, Wong FS, et al. Topical steroid therapy induces protolerogenic changes in Langerhans cells in human skin. Immunology 2015;146:411-422.

19. Zhu L, Zhang C, Chuck RS. Topical steroid and non-steroidal anti-inflammatory drugs inhibit inflammatory cytokine expression on the ocular surface in the botulinum toxin B-induced murine dry eye model. Mol Vis 2012;18: 1803-1812.

20. Aksoy MO, Li X, Borenstein M, Yi Y, Kelsen SG. Effects of topical corticosteroids on inflammatory mediator-induced eicosanoid release by human airway epithelial cells. J Allergy Clin Immunol 1999;103:1081-1091.

21. Matsui K, Tamai S, Ikeda R. Betamethasone, but not tacrolimus, suppresses the development of Th2 cells mediated by Langerhans cell-like dendritic cells. Biol Pharm Bull 2016;39:1220-1223.

22. Lee HK, Ryu IH, Seo KY, Hong S, Kim HC, Kim EK. Topical $0.1 \%$ prednisolone lowers nerve growth factor expression in keratoconjunctivitis sicca patients. Ophthalmology 2006; 113:198-205.

23. Kagawa $Y$, Izawa K, Yano H, Kamei C. Synergetic effects of prednisolone and olopatadine on atopic dermatitis model of hairless mice. Pharmacology 2010;85:286-294.

24. Bigliardi-Qi M, Lipp B, Sumanovski LT, Buechner SA, Bigliardi PL. Changes of epidermal mu-opiate receptor expression and nerve endings in chronic atopic dermatitis. Dermatology 2005;210:91-99.

25. Arndt J, Smith N, Tausk F. Stress and atopic dermatitis. Curr Allergy Asthma Rep 2008;8:312-317.

26. Bigliardi PL, Stammer H, Jost G, Rufli $T$, Büchner $S$, Bigliardi-Qi M. Treatment of pruritus with topically applied opiate receptor antagonist. J Am Acad Dermatol 2007;56: 979-988.

27. Yoshida A, Mobarakeh JI, Sakurai E, Sakurada S, Orito T, Kuramasu A, et al. Intrathecally-administered histamine facilitates nociception through tachykinin NK1 and histamine $\mathrm{H} 1$ receptors: a study in histidine decarboxylase gene knockout mice. Eur J Pharmacol 2005;522:55-62.

28. Nakasone T, Sugimoto $Y$, Kamei $C$. The interaction between histamine $\mathrm{H} 1$ receptor and $\mu$ - opioid receptor in scratching behavior in ICR mice. Eur J Pharmacol 2016;777:124-128.

29. Sugimoto $Y$, Umakoshi K, Nojiri N, Kamei C. Effects of histamine $\mathrm{H} 1$ receptor antagonists on compound 48/80-induced scratching behavior in mice. Eur J Pharmacol 1998;351:1-5. 